\title{
Sarcoptes scabiei: Ectoparásito de la sarna
}

\section{Sarcoptes scabiei: Ectoparasite of scabies}

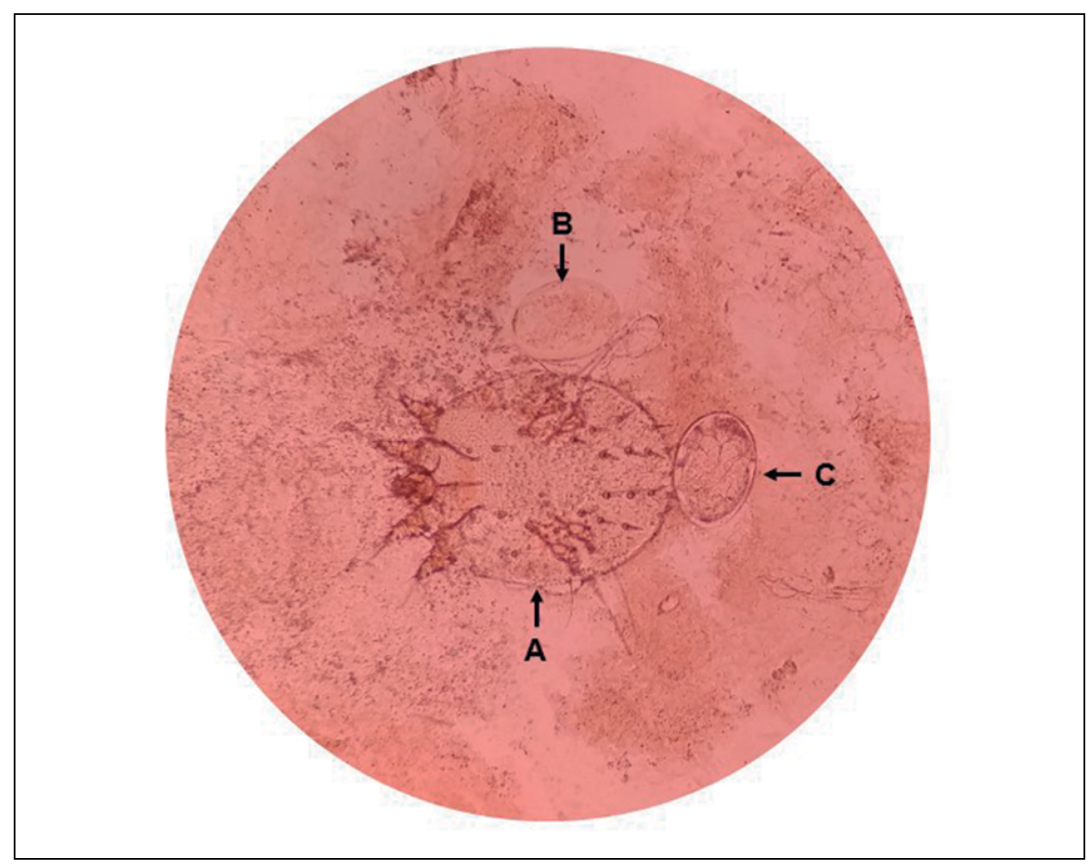

Figura 1. Adulto y huevo de Sarcoptes scabiei, ampliación de 100 aumentos: A) hembra adulta mostrando el cuarto par patas; B) Huevo recién puesto; C) Huevo conteniendo larva a punto de eclosionar.

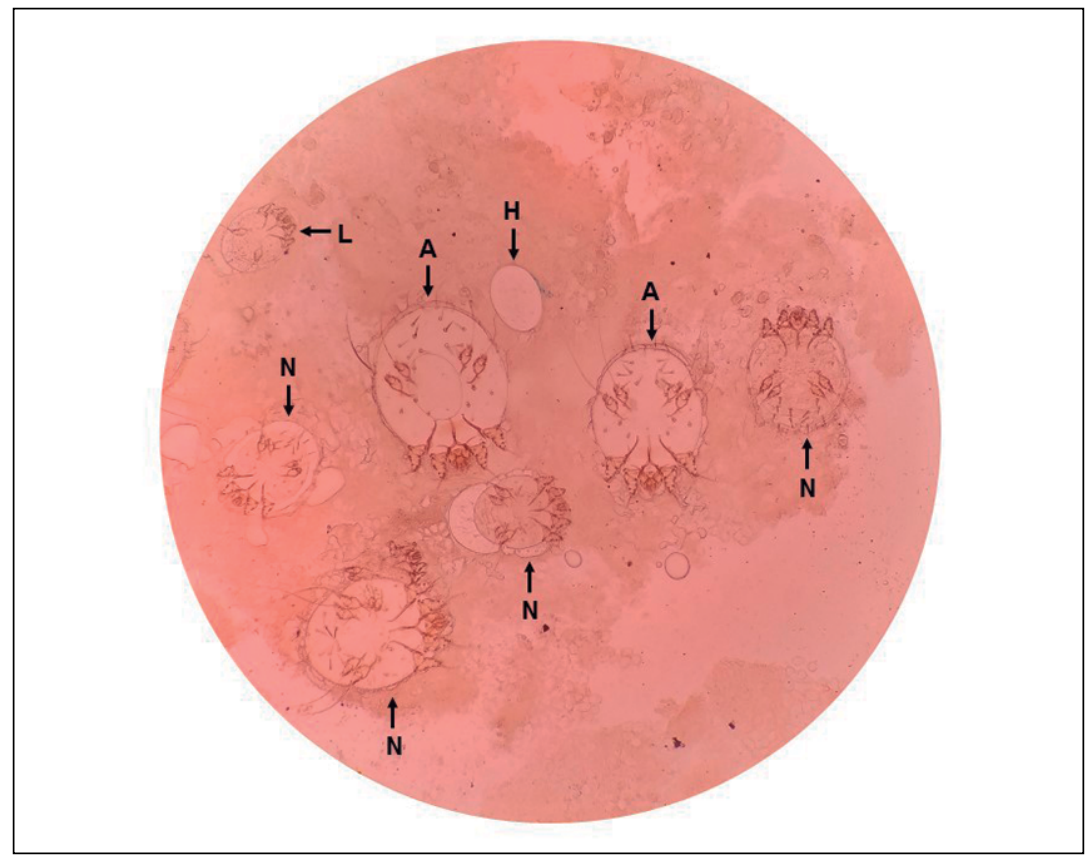

Figura 2. Estados biológicos de Sarcoptes scabiei, ampliación de 100 aumentos: H) Huevo; L) Larva; N) Ninfas hembras; A) Adultos hembras, izquierda conteniendo huevo en el abdomen. 


\title{
Sarcoptes scabiei: Ectoparásito de la sarna
}

\author{
Sarcoptes scabiei: Ectoparasite of scabies
}

Sarcoptes scabiei var hominis, es un ectoparásito que vive en la epidermis de la piel humana, pertenece a la clase Arácnida, subclase Acari, orden Astigmata, familia Sarcoptidae, Subfamilia Sarcoptinae. El adulto es blanco cremoso, es ciego y sus quelíceros de su boca están provistos de dientes, con un cuerpo aplanado, translucente y oval. Su desarrollo biológico, evoluciona a través de cuatro estados: huevo, larva, ninfa y adulto. La hembra adulta es más grande que el macho, mide de 0,3 a 0,5 mm de longitud por $0,3 \mathrm{~mm}$ de ancho. Los estadios de ninfa y adulto tienen cuatro pares de patas; la forma larvaria solo tiene tres pares. El cuarto par de patas de la hembra es diferencial porque termina en largas espinas; en el macho son pedunculadas y convexas. El ácaro hembra ingresa al estrato córneo a una velocidad de 0,5 a $5 \mathrm{~mm}$ por día. Después de la cópula dan inicio a la ovoposición de dos a cinco huevos al día junto a pequeños gránulos de excremento, oscuros, ovales e irritantes. Los huevos ovales, miden 0,10 a 0,15 mm de longitud. Tres a cuatro días después se convierten en larvas que abandonan la madriguera y maduran en la superficie de la piel en adultos. La vida útil de un ácaro hembra es de cuatro a seis semanas, durante las cuales pone alrededor de 40 a 50 huevos ${ }^{1,2}$.

La sarna es una de las enfermedades tropicales desatendidas más comunes de la piel, afectando cada año entre 150 a 200 millones de personas en el mundo, en particular a niños. La infección tiene un impacto mayor en ambientes de hacinamiento con malas condiciones de vida y la opción terapéutica actual es con un acaricida tópico o tratamiento oral con ivermectina. La transmisión ocurre principalmente a través del contacto de piel a piel y, con menos frecuencia, a través de fómites dentro de un entorno contaminado por ácaros del paciente.

El estandar de oro en el diagnóstico sigue siendo la visualización directa del parásito, así como los huevos, fragmentos de cáscara de huevo o gránulos fecales de ácaros, mediante el examen microscópico óptico de un raspado de piel ${ }^{3}$. El tratamiento previo de la muestra con hidróxido de potasio al 10\% ayuda a una visualización mejor de las estructuras parasitarias (Figura 1 y 2).

\section{Referencias bibliográficas}

1.- Arora P, Rudnicka L, Sar-Pomian M, Wollina U, Jafferany M, Lotti T, et al. Scabies: A comprehensive review and current perspectives. Dermatol Ther 2020; 33: e13746. doi: 10.1111/dth.13746.

2.- Tincopa-Wong OW. Escabiosis (sarna): Revisión epidemiológica, clínica, patogénica y terapéutica. Dermatol Peru 2017 (4); 27 (2): 19 -107.

3.- Bernigaud C, Fischer K, Chosidow O. The management of scabies in the 21 st century: past, advances and potentials. Acta Derm Venereol 2020; 100(9): adv00112. doi: 10.2340/00015555-3468.

\author{
Roberto Ventura-Flores ${ }^{1}$ \\ ${ }^{\prime}$ Laboratorio de Investigación, Hospital Regional Lambayeque, Chiclayo-Perú.
}

